\section{(2) OPEN ACCESS}

\title{
Impact of depressive symptoms on worklife expectancy: a longitudinal study on Danish employees
}

\author{
Jacob Pedersen (10, ' Sannie Vester Thorsen, ${ }^{1}$ Malene Friis Andersen, ${ }^{1}$ \\ Therese N Hanvold, ${ }^{2}$ Vivi Schlünssen, ${ }^{3}$ Ute Bültmann (i) ${ }^{4}$
}

\begin{abstract}
- Additional material is published online only. To view please visit the journal online (http://dx.doi.org/10.1136/ oemed-2019-105961).

${ }^{1}$ The National Research Center for the Working Environment, Copenhagen, Denmark

${ }^{2}$ STAMI - the National Institute of Occupational Health, Oslo, Norway

${ }^{3}$ Department of Occupational Medicine, Danish Ramazzini Centre, Aarhus University Hospital, Aarhus, Denmark ${ }^{4}$ Health Sciences, Community and Occupational Medicine, University of Groningen, University Medical Center Groningen, Groningen, The Netherlands
\end{abstract}

\section{Correspondence to} Dr Jacob Pedersen, Nationale Forskningscenter for Arbejdsmiljo, Copenhagen 2100, Denmark; jpe@nfa.dk

Received 16 May 2019 Revised 30 August 2019 Accepted 7 September 2019

Published Online First

3 October 2019

\section{ABSTRACT}

Objective Depressive symptoms are associated with sickness absence, work disability and unemployment, but little is known about worklife expectancy (WLE). This study investigates the impact of depressive symptoms on the WLE of a large sample of Danish employees. Methods We used occupational health survey data of 11967 Danish employees from 2010 and linked them with register data on salary and transfer payments from 2010 to 2015. Depressive symptoms were selfreported using the Major Depression Inventory. We used multistate data and a life table approach with Cox proportional hazard modelling to estimate the WLE of employees, expressed by time in work, unemployment and sickness absence. Separate analyses were conducted for sex and employees with a voluntary early retirement pension scheme. Using age as time axis, we used inverse probability weights to account for differences in educational level, sector, body mass index, smoking habits and loss of employment during sickness absence. Results The WLE of employees reporting depressive symptoms was shorter compared with those not reporting depressive symptoms; that is, the expected time in unemployment and sickness absence was longer, while the expected time in work was shorter. The shorter WLE was most pronounced in women; for example, a 40-yearold woman with depressive symptoms can expect 3.3 years less in work, 0.8 years more in unemployment and 0.7 years more in sickness absence. Employees with a voluntary early retirement pension scheme showed an even lower WLE.

Conclusions Our study showed a meaningful impact of depressive symptoms on the WLE of Danish employees using a multistate framework.

\section{INTRODUCTION}

Mental disorders are the leading cause of disease burden worldwide ${ }^{1}$ and affect individuals, families, workplaces and society. Recently, the European Working Conditions Survey showed that up to $17 \%$ of the general working population reported scores indicative of depression. ${ }^{2}$ Work and health surveillance data in Denmark showed that more and more employees report depressive symptoms, from $8.5 \%$ in 2012 to $9.0 \%$ in $2014,10.9 \%$ in 2016, and $11.0 \%$ in 2018, respectively. ${ }^{3}$ Depressive symptoms are associated with unemployment and with substantial work impairment in terms of lost workdays and reduced productivity. ${ }^{4-10}$

\section{Key messages}

What is already known about this subject?

- Depressive symptoms have a negative impact on social and work functioning, productivity, and labour market affiliation.

- Worklife expectancy is a useful measure to inform preventive policies and practices.

What are the new findings?

- Our study, applying a multistate framework with a life course perspective, showed that depressive symptoms have a significant impact on worklife expectancy.

- Employees reporting depressive symptoms spend less time in work and more time in sickness absence and unemployment compared with employees not reporting depressive symptoms.

- The worklife expectancy of employees with an early retirement pension scheme and depressive symptoms is shorter compared with those without this pension scheme.

\section{How might this impact on policy or clinical} practice in the foreseeable future?

- Our findings underline the need for effective policies and interventions to prevent depressive symptoms in the working population to add more healthy and productive years to the working life.

With an onset early in life, mental health problems are associated with a disproportionally high burden of disease among young people and may have devastating effects on the whole life course. $^{11} 12$ Therefore, means to promote mental health and well-being of people of all ages are becoming increasingly important to maintain a high labour market participation. ${ }^{13} 14$

Despite the negative impact of depressive symptoms on labour market affiliation and work participation, it is today not clear to what extent depressive symptoms impact the worklife expectancy (WLE), a measure crucial to set priorities for preventive policies and practices. WLE is an estimation of the expected time within the labour market until retirement. Since the 1970 s, WLE has gained 


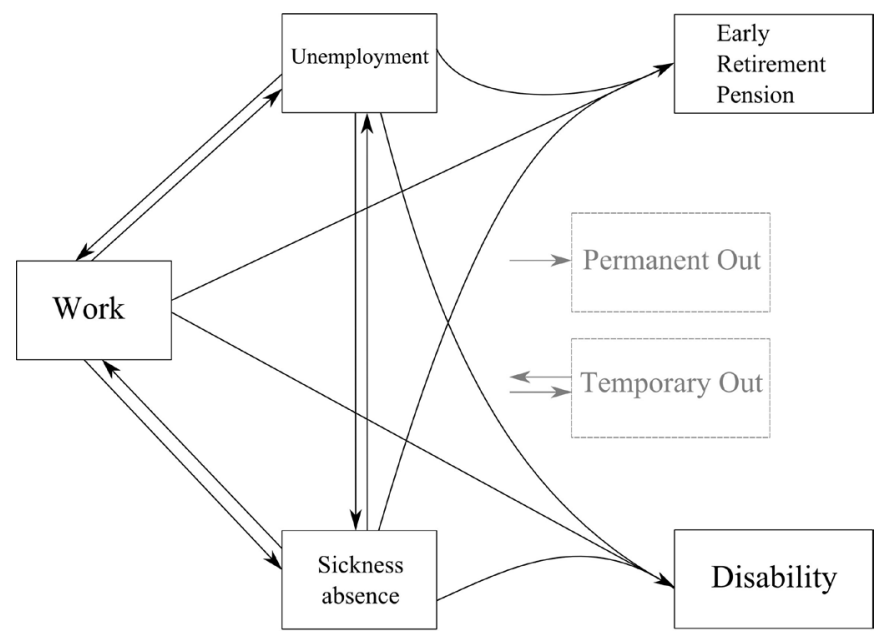

Figure 1 The multistate model with the seven states: work, sickness absence, unemployment, disability retirement pension (disability), early retirement pension scheme, temporary exclusion from the labour market (temporary out) and permanent exclusion from the labour market (permanent out). The eight transitions of primary interest are represented by non-interrupted arrows (Pedersen and Bjorner ${ }^{20}$ ).

increasing attention as models based on multistate models and transition probabilities have been developed. ${ }^{15-22}$

In the present study on the impact of depressive symptoms on WLE, the concept of WLE was expanded to capture next to the labour market state, 'work' and also 'unemployment' and 'sickness absence' before retirement, as recently proposed by Pedersen and Bjorner. ${ }^{20}$ The expansion of the WLE concept corresponds with the flexible Danish labour market and allows more detailed analyses of transitions between labour market states among employees with depressive symptoms. Hence, the aims of this study were to investigate the impact of depressive symptoms on the WLE of occupationally active male and female employees. As the Danish system offers a voluntary and very common early retirement pension (ERP) scheme, which may affect the WLE of employees with depressive symptoms, separate analyses were conducted for employees with the voluntary ERP scheme.

\section{METHODS}

\section{Jurisdictional context: the Danish labour market}

The Danish labour market is characterised by a flexicurity system with high labour market participation rates $(71 \%$ for women and $75 \%$ for men), ${ }^{23}$ low formal employment protection, generous and accessible social benefits, and a high turnover of the workforce. $^{24}$ The official retirement age in Denmark is currently 65 years, but the system also allows earlier retirement. Possibilities of early retirement concern 'disability retirement pension', which is accessible for all, gradual retirement with labour market affiliation on special terms (eg, flex-job), and voluntary 'early retirement pension'. The voluntary ERP scheme is an insurance and saving scheme. Employees pay a part of their salary for 30 years to be able to retire as early as 5 years before the official retirement age.

\section{Study design}

This longitudinal study uses data on depressive symptoms from the Danish Work Environment Cohort Study (DWECS). ${ }^{25}$ DWECS data on depressive symptoms are linked with register data on labour market affiliation in 2010-2015 from the Labour Market Accountant Register (LMAR) by Statistics Denmark.

The DWECS started in 1990 and had repeated waves every fifth year until 2010. Each wave contains a representative sample of the Danish population aged $18-59$ years. ${ }^{25}$ For the present study, we used DWECS data from 2010, including a total of 14453 respondents (48\% response). ${ }^{26}$ Of the respondents, 11967 (83\%) answered the questions on depressive symptoms.

LMAR contains information on all Danish citizens with a labour market affiliation from 2008 onwards. LMAR contains daily salary payments and daily payments of all major social benefits on an individual level. The Personal Income Register was used to identify respondents who had joined the voluntary ERP scheme $(n=4205$ respondents, 35\%). Information on mortality was retrieved from the Danish Death Register.

\section{Depressive symptoms}

Depressive symptoms in 2010 were measured once with the 12-item Major Depression Inventory (MDI), with scores ranging between 0 and 50.2728 The MDI has been validated in both the general population and among patients in the clinical setting. ${ }^{27} 2930$ In the present study, an MDI score of $\geq 21$ was used to identify employees with a depressive symptom level, indicative of mild depression. ${ }^{31} 32$

\section{Labour market affiliation}

Labour market affiliation was measured by seven labour market states based on the longitudinal registrations of the LMAR register: work, unemployment, sickness absence, disability retirement pension, ERP, temporary out of the labour market and permanently out of the labour market. The work state reflects the periods when a person receives salary payments and no other major social benefit. The unemployment state concerns the periods when a person receives any type of social benefit for unemployment, given the condition that the person is available for work. The sickness absence state reflects the periods when a person is long-term sick-listed and receives sickness absence benefits (defined as >21 consecutive days before 2012 and $>30$ days after 2012). The disability retirement pension state concerns the time after a person had been awarded disability pension because he/she is not able to work, for example, due to a chronic illness. The ERP state is at hand when an ERP scheme member voluntarily retires. The temporary out of the labour market state concerns periods of maternity leave, education and emigration, and also periods without registration of any income. The permanently out of the labour market state concerns the time when a person receives any type of old-age pension (except for ERP) and death.

\section{Covariates}

Baseline information on educational level (basic school, high school, vocational school, short and medium higher education, bachelor's and long higher education) and sector (manufacturing, construction, graphical, transport and wholesale, commerce, service, agriculture, caretaking and health, education and research, finance and public offices and administration, and private offices and administration) was obtained from Statistics Denmark in 2010. Additional baseline information on body mass index (BMI) (underweight: BMI <18.5; normal: BMI between 18.5 and 24.9; overweight: BMI between 25.0 and 29.9; and obesity: BMI >29.9) and smoking (smoker, non-smoker) was derived from DWECS 2010. In addition, information from 

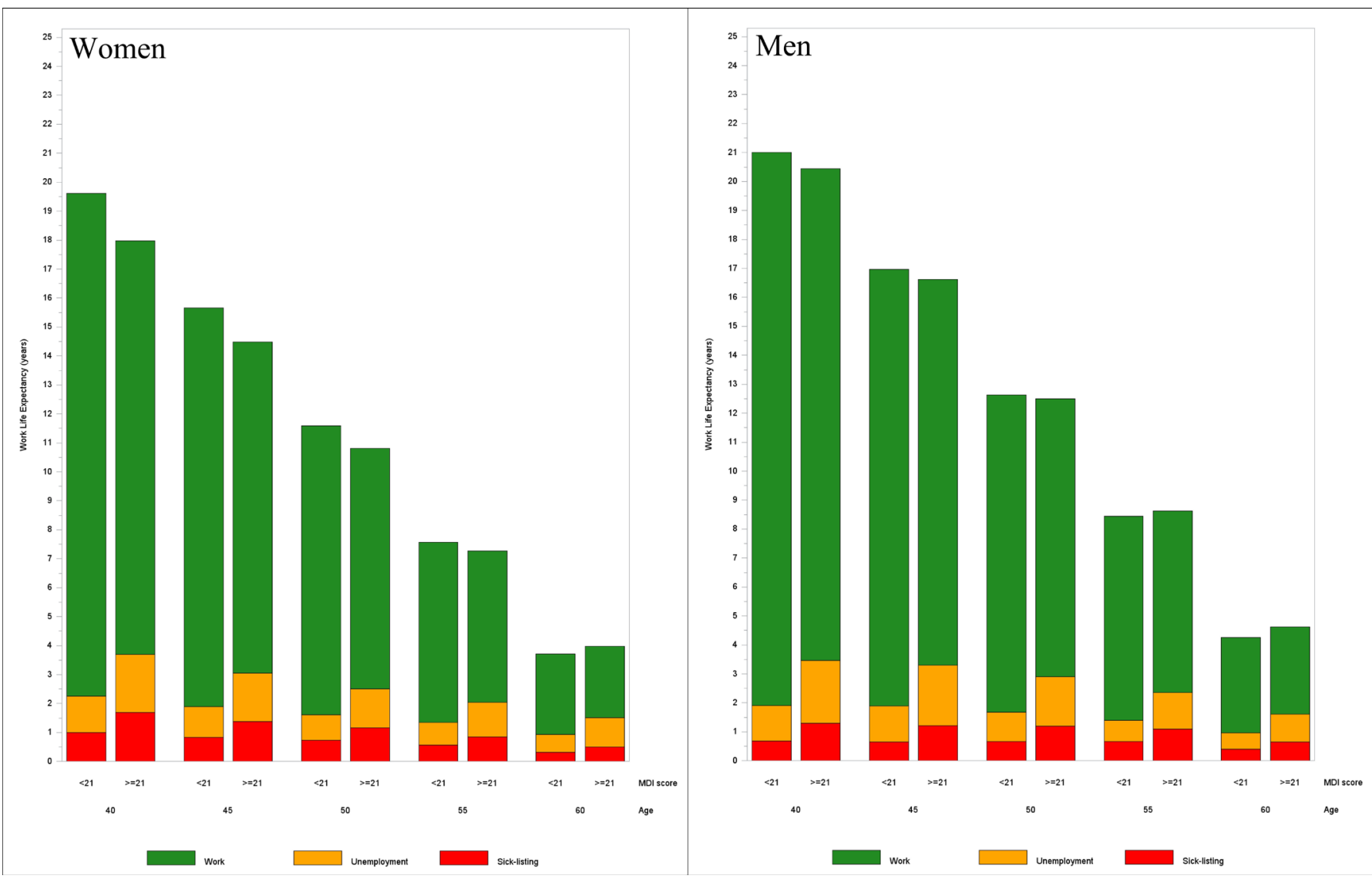

Figure 2 Worklife expectancy in years for employees without ERP scheme, by depressive symptom level (MDI $\geq 21)$, sex and age. ERP, early retirement pension; MDI, Major Depression Inventory.

LMAR was used for a repeated adjustment of the employment status during periods of sickness absence only.

\section{Statistical analyses}

Multistate modelling was used to analyse the transition probabilities for the labour market affiliation model using age as the underlying time axis, going from 18 to 65 years in steps of hundredths. The work, unemployment, sickness absence and temporary out of the labour market states were considered recurrent states, that is, several and repeated transitions from or to these states are possible. The disability retirement pension state, the ERP state and the permanently out of the labour market state were all considered absorbing states, as it is not possible to go back to the recurrent states when a transition to one of these states has occurred. A person enters the model by left truncation at the age of answering the DWECS survey and exits the model by right censoring, which happens when the follow-up period ends or the person turns 65 years.

Figure 1 shows the multistate model with boxes illustrating the labour market states and arrows showing the possible transitions. The temporary out of the labour market state and the permanently out of the labour market state are included to ensure independent censuring, as the probability of, for example, leave due to education, receiving old-age pension and even death may not be independent of the level of depressive symptoms. Therefore, these transitions cannot be considered as censuring.

To investigate the WLE by depressive symptom level, we followed the procedure introduced by Pedersen and Bjorner. ${ }^{20}$ The initial analyses included only employees without the ERP scheme $(n=7762)$. Additionally, the analyses were repeated among employees with the ERP scheme $(n=4205)$ (see online supplementary material figure and tables).

All analyses included stabilised inverse probability weights for an even distribution of the covariates. The weights were estimated for each data record using the dichotomous depressive symptom level as the dependent variable in a logistic regression. For each one-hundredth of age, we estimated a matrix, containing the instantaneous hazard of all 18 transitions and the 7 instantaneous state occupation probabilities. This was done for each group of ERP, sex and for those with an MDI score below 21. We used the Chapman-Kolmogorov equation and the instantaneous hazard matrixes to gain the transitions specific baseline hazards and the state occupation probabilities. We estimated the expected state duration as the area under the state occupation probability curves until 65 years of age, with different initial ages of $40-60$ years by 5 -year intervals. The analysis so far corresponds to using a multistate life table approach.

We used a Cox regression on the long format multistate data with the dichotomous depressive symptom level as the only variable and a reference value of below 21 on the MDI. We included the stabilised weighting and performed a separate Cox regression by ERP status and sex. We then used the estimates from the Cox regression to adjust the respective instantaneous hazard matrixes of the individuals with an MDI score below 21. After this, we repeated the rest of the above-specified procedure to gain the expected state duration of individuals with an MDI score equal to or above 21 . The $95 \%$ confidence limits were calculated using the Greenwood variance. In the Cox regression, the transitions towards the absorbing states were collapsed into one transition to secure a high number of events. 


\begin{tabular}{|c|c|c|}
\hline & Women & Men \\
\hline & $\mathrm{n}(\%)$ & n (\%) \\
\hline Total (n) & 4051 & 3711 \\
\hline \multicolumn{3}{|l|}{ Age group (years) } \\
\hline $18-29$ & $1072(26.5)$ & $843(22.7)$ \\
\hline $30-39$ & $1184(29.2)$ & $972(26.2)$ \\
\hline $40-49$ & $1251(30.9)$ & $1198(32.3)$ \\
\hline $50-59$ & $472(11.7)$ & $614(16.5)$ \\
\hline $60-64$ & $72(1.8)$ & $84(2.3)$ \\
\hline \multicolumn{3}{|l|}{ Highest educational level } \\
\hline Basic school & $577(14.2)$ & $625(16.8)$ \\
\hline High school & $561(13.8)$ & $384(10.3)$ \\
\hline Vocational school & $1144(28.2)$ & $1296(34.9)$ \\
\hline Short and medium higher education & $1056(26.1)$ & $694(18.7)$ \\
\hline Bachelor's and long higher education & $636(15.7)$ & $647(17.4)$ \\
\hline Not available & $77(1.9)$ & $65(1.8)$ \\
\hline \multicolumn{3}{|l|}{ Sector } \\
\hline Manufacturing & $236(5.8)$ & $460(12.4)$ \\
\hline Constructions & $19(0.5)$ & $170(4.6)$ \\
\hline Graphic & $21(0.5)$ & $30(0.8)$ \\
\hline Transport and wholesale & $170(4.2)$ & $335(9)$ \\
\hline Trade & $161(4)$ & $77(2.1)$ \\
\hline Service trade & $140(3.5)$ & $209(5.6)$ \\
\hline Agriculture & $10(0.2)$ & $40(1.1)$ \\
\hline Social security and health & $972(24)$ & $205(5.5)$ \\
\hline Education and research & $280(6.9)$ & $211(5.7)$ \\
\hline Finance, public offices and administration & $291(7.2)$ & $215(5.8)$ \\
\hline Private offices and administration & $187(4.6)$ & $194(5.2)$ \\
\hline Not available & $1564(38.6)$ & $1565(42.2)$ \\
\hline \multicolumn{3}{|l|}{ BMI } \\
\hline Obesity (BMI >29.9) & 477 (11.8) & $464(12.5)$ \\
\hline Overweight (BMI between 25.0 and 29.9) & $947(23.4)$ & $1457(39.3)$ \\
\hline Normal (BMI between 18.5 and 24.9) & $2413(59.6)$ & $1711(46.1)$ \\
\hline Underweight (BMI <18.5) & $131(3.2)$ & $28(0.8)$ \\
\hline Not available & $83(2)$ & $51(1.4)$ \\
\hline \multicolumn{3}{|l|}{ Smoking } \\
\hline Smoker & $915(22.6)$ & $961(25.9)$ \\
\hline Non-smoker & $3083(76.1)$ & $2706(72.9)$ \\
\hline Not available & $53(1.3)$ & $44(1.2)$ \\
\hline \multicolumn{3}{|l|}{ Depression by MDI score } \\
\hline Depression (MDI $\geq 21$ ) & $913(22.5)$ & $600(16.2)$ \\
\hline No depression $(\mathrm{MDI}<21)$ & $3138(77.5)$ & 3111 (83.8) \\
\hline
\end{tabular}

The final estimates express the average expected time in work, unemployment and sickness absence. The time sum will always be lower than the absolute difference between the selected age and the official old-age pension age because of different (working) life courses, including, for example, periods of temporary labour market leave for education, receiving disability pension and early deaths. As the WLE of employees aged 18-39 years is more uncertain compared with older employees, reflecting a looser labour market affiliation with several periods of maternity leave and education, we only show the WLE of employees older than 40 years (figure 2 and online supplementary figure 1 ), although all ages were included in the matrix estimations and the Cox regression analyses. The use of inverse probability weights implies that for a comparison of the WLE between groups, an identical distribution of the listed covariates is assumed.
All analyses were conducted with SAS V.9.4 software using PROC PHREG and custom-made coding.

\section{RESULTS}

\section{Baseline characteristics}

Table 1 shows the baseline characteristics of 7762 employees without the ERP scheme. The average age of the study population is 39 (SD 11) years, with slightly more women than men $(52 \%$ vs $48 \%)$. The majority of employees finished vocational education. Most women worked in the social security and health sector, while most men worked in manufacturing. Women more often reported depressive symptoms than men (23\% vs $16 \%)$.

Online supplementary table 1 shows the baseline characteristics of 4205 employees with the ERP scheme. The average age of these employees is 52 (SD 8) years, and 57\% were men. Again, the majority of employees finished vocational education and are employed in social security and health (39\% women) or manufacturing ( $17 \%$ men). Women more often reported depressive symptoms than men (17\% vs 11\%).

\section{Depressive symptoms and WLE}

Figure 2 shows the sex-specific WLE for the 7762 employees without the ERP scheme, expressed as time in work, unemployment and sickness absence (in years). The WLE is shown by depressive symptom level for age 40-60 years. Table 2 shows the corresponding WLE estimates.

The WLE results in table 2 show that, for example, a 40-year-old man without depressive symptoms has a total WLE of 21.6 years, of which 19.9 years were in work, 1.3 years in unemployment and 0.7 year in sickness absence. For a woman of the same age with depressive symptoms, the WLE is 2.3 years shorter in work (12\%), while the time in unemployment and sickness absence is 0.9 years $(69 \%)$ and 0.6 year $(53 \%)$ longer, respectively. Overall, the WLE is on average 5\% shorter for women and $1 \%$ shorter for men reporting depressive symptoms. When looking at the separate labour market states, women and men with depressive symptoms showed an average shorter time in work of $16 \%$ and $13 \%$, respectively. The expected time in unemployment was $60 \%$ longer for women and $66 \%$ longer for men with depressive symptoms, and the expected time in sickness absence was 58\% longer for women and 72\% longer for men, respectively. The shorter expected time in work is significant, when comparing the confidence limits of women with and without depressive symptoms for the age of 40 years. For other ages and sex, the confidence limits in table 2 show no significant differences in the expected time in work, unemployment and sickness absence. Overall, the results show a stable tendency of shorter time in work, longer time in unemployment and longer time in sickness absence for all analysed age groups.

Online supplementary figure 1 shows the results for employees with the ERP scheme. The results in online supplementary table 2 show that, for example, a 40-year-old woman with depressive symptoms can expect 4.7 years less in work than a 40 -year-old woman without depressive symptoms, and 0.2 more years of unemployment and 0.4 more years of sickness absence. Similarly, a 40-year-old man can expect 5 years less in work, 0.2 years more in unemployment and 0.4 more in sickness absence. The average decrease in time in work is $21 \%$ for both women and men. The average increased time in unemployment is $23 \%$ for women and $18 \%$ for men, and the average increased time in sickness absence is 59\% for women and 79\% for men, respectively. The decrease in expected time in work is statistically significant, when comparing the CI for employees with 


\begin{tabular}{|c|c|c|c|c|c|c|c|c|}
\hline Sex & Age & MDI score & Work $(95 \% \mathrm{CL})$ & Diff (\%) & Unemployment (95\% CL) & Diff (\%) & Sick $(95 \% \mathrm{CL})$ & Diff (\%) \\
\hline \multirow[t]{10}{*}{ Female } & \multirow[t]{2}{*}{40} & $<21$ & $17.9(16.5-19.2)$ & \multirow[t]{2}{*}{-18.4} & $1.3(0.5-2.1)$ & \multirow[t]{2}{*}{61.5} & $1.0(0.3-1.8)$ & \multirow[t]{2}{*}{70.0} \\
\hline & & $\geq 21$ & $14.6(13.1-16.1)$ & & $2.1(0.9-3.2)$ & & $1.7(0.7-2.8)$ & \\
\hline & \multirow[t]{2}{*}{45} & $<21$ & $14.3(13.1-15.5)$ & \multirow[t]{2}{*}{-17.5} & $1.1(0.4-1.8)$ & \multirow[t]{2}{*}{54.5} & $0.9(0.2-1.5)$ & \multirow[t]{2}{*}{55.6} \\
\hline & & $\geq 21$ & $11.8(10.5-13.1)$ & & $1.7(0.7-2.8)$ & & $1.4(0.5-2.3)$ & \\
\hline & \multirow[t]{2}{*}{50} & $<21$ & $10.5(9.5-11.5)$ & \multirow[t]{2}{*}{-17.1} & $0.9(0.3-1.6)$ & \multirow[t]{2}{*}{55.6} & $0.8(0.2-1.4)$ & \multirow[t]{2}{*}{50.0} \\
\hline & & $\geq 21$ & $8.7(7.5-9.8)$ & & $1.4(0.5-2.3)$ & & $1.2(0.4-2.1)$ & \\
\hline & \multirow[t]{2}{*}{55} & $<21$ & $6.7(5.9-7.5)$ & \multirow[t]{2}{*}{-16.4} & $0.8(0.2-1.4)$ & \multirow[t]{2}{*}{62.5} & $0.6(0.1-1.1)$ & \multirow[t]{2}{*}{50.0} \\
\hline & & $\geq 21$ & $5.6(4.7-6.5)$ & & $1.3(0.4-2.1)$ & & $0.9(0.2-1.6)$ & \\
\hline & \multirow[t]{2}{*}{60} & $<21$ & $3.3(2.7-3.8)$ & \multirow[t]{2}{*}{-12.1} & $0.6(0.1-1.1)$ & \multirow[t]{2}{*}{66.7} & $0.3(-0.1-0.8)$ & \multirow[t]{2}{*}{66.7} \\
\hline & & $\geq 21$ & $2.9(2.3-3.5)$ & & $1.0(0.3-1.8)$ & & $0.5(-0.1-1.2)$ & \\
\hline \multirow[t]{10}{*}{ Male } & \multirow[t]{2}{*}{40} & $<21$ & $19.6(18.5-20.7)$ & \multirow[t]{2}{*}{-11.7} & $1.3(0.5-2.0)$ & \multirow[t]{2}{*}{69.2} & $0.7(0.1-1.3)$ & \multirow[t]{2}{*}{85.7} \\
\hline & & $\geq 21$ & $17.3(15.9-18.7)$ & & $2.2(1.1-3.4)$ & & $1.3(0.4-2.3)$ & \\
\hline & \multirow[t]{2}{*}{45} & $<21$ & $15.6(14.6-16.5)$ & \multirow[t]{2}{*}{-12.8} & $1.3(0.5-2.1)$ & \multirow[t]{2}{*}{69.2} & $0.7(0.1-1.3)$ & \multirow[t]{2}{*}{71.4} \\
\hline & & $\geq 21$ & $13.6(12.4-14.8)$ & & $2.2(1.1-3.3)$ & & $1.2(0.3-2.2)$ & \\
\hline & \multirow[t]{2}{*}{50} & $<21$ & $11.5(10.6-12.3)$ & \multirow[t]{2}{*}{-13.9} & $1.1(0.4-1.7)$ & \multirow[t]{2}{*}{63.6} & $0.7(0.1-1.3)$ & \multirow[t]{2}{*}{71.4} \\
\hline & & $\geq 21$ & $9.9(8.9-11.0)$ & & $1.8(0.9-2.7)$ & & $1.2(0.3-2.1)$ & \\
\hline & 55 & $<21$ & $7.6(6.9-8.2)$ & -13.2 & $0.8(0.2-1.3)$ & 62.5 & $0.7(0.2-1.2)$ & 57.1 \\
\hline & & $\geq 21$ & $6.6(5.8-7.4)$ & & $1.3(0.6-2.1)$ & & $1.1(0.4-1.9)$ & \\
\hline & 60 & $<21$ & $3.8(3.3-4.2)$ & -13.2 & $0.6(0.2-1.0)$ & 66.7 & $0.4(0.0-0.8)$ & 75.0 \\
\hline & & $\geq 21$ & $3.3(2.8-3.9)$ & & $1.0(0.4-1.6)$ & & $0.7(0.1-1.2)$ & \\
\hline
\end{tabular}

$\mathrm{CL}$, confidence limits; Diff, per cent difference in WLE between MDI scores by sex and age; ERP, early retirement pension; MDI, Major Depression Inventory; WLE, worklife expectancy.

and without depressive symptoms, for all age groups and sexes. For the expected time in unemployment and sickness absence, no significant differences were found for employees with and without depressive symptoms or for male and female employees.

Table 3 shows the results of the respective Cox regression on the long formatted multistate data. The results show that women with depressive symptoms have a significantly higher risk of having a transition from work to sickness absence and unemployment, and more than a threefold risk of a transition from work/unemployment/sick to disability, when compared with a woman without depressive symptoms. Women additionally have a significantly lower probability of a transition from sickness absence to work (32\%) and from unemployment to work (25\%). The results show that men with depressive symptoms also have a significantly higher risk of a transition from work to sick $(70 \%)$ and unemployment (50\%), and more than a fivefold risk of a transition to disability pension, when compared with men without depressive symptoms. The results additionally show that men have less probability of transitioning from unemployment to work (29\%).

The results in online supplementary table 3 for women and men with the ERP scheme were similar to those for employees without the ERP scheme (table 3). Online supplementary table 3 shows that women and men with depressive symptoms have almost a twofold probability of early retirement by the ERP scheme when compared with women and men without depressive symptoms.

\section{DISCUSSION}

The present study is, to the best of our knowledge, the first to examine the impact of depressive symptoms on WLE. Most previous studies have investigated the impact of depressive symptoms on sickness absence and unemployment separately, without a multistate framework or a life course perspective.

Our study showed that depressive symptoms may have a lifelong impact on labour market affiliation. A 40-year-old man reporting depressive symptoms without ERP will spend approximately 2 years less in work before retirement compared with a man not reporting depressive symptoms. In women, the corresponding difference in time less in work is 3 years. In addition to lost time in work, our study showed that a 40-year-old employee reporting depressive symptoms will on average receive 1.5 more years of unemployment and sickness absence benefits compared with an employee not reporting depressive symptoms.

The study also provided suggestive evidence that employees in the Danish ERP scheme and reporting depressive symptoms will retire even earlier; that is, a 40-year-old man or woman will spend 5 years less in work compared with employees without ERP. The receipt of unemployment and sickness absence benefits is 0.6 years in those with ERP, compared with 1.5 years in those without ERP, indicating that employees may use the ERP scheme to avoid unemployment and long-term sickness absence benefits.

While our findings are in concordance with previous studies on mental health problems and associated sickness absence and unemployment, ${ }^{33-36}$ we demonstrated for the first time how many years of active labour market participation are lost when reporting depressive symptoms. Likewise, we also showed for the first time how many years of the worklife employees reporting depressive symptoms are expected to be in unemployment and/ or sickness absence.

Our study further showed that employees reporting depressive symptoms have less time in work, and more time in unemployment and sickness absence, for both men and women. The labour market affiliation of men and women is different in most countries; for example, men retire at an older age than women, and women have more sickness absence than men. ${ }^{37}$ Our study indicates that depressive symptoms partly may explain the sex difference in labour market affiliation, as women more often report depressive symptoms than men. The findings additionally suggest a slight difference between younger men and women reporting depressive symptoms, with even less time in work for the women than the men. 
Table 3 Estimates of the Cox proportional hazard model for employees without the ERP scheme

\begin{tabular}{|c|c|c|c|}
\hline Transition & $\begin{array}{l}\text { MDI } \\
\text { score }\end{array}$ & $\begin{array}{l}\text { Women } \\
\text { HR }(95 \% \mathrm{CL})\end{array}$ & $\begin{array}{l}\text { Men } \\
\text { HR }(95 \% \mathrm{CL})\end{array}$ \\
\hline \multirow[t]{2}{*}{ Work to sick } & $<21$ & $1.59(1.04-2.45)^{*}$ & $1.70(1.10-2.65)^{*}$ \\
\hline & $\geq 21$ & $1.00(-)$ & $1.00(-)$ \\
\hline \multirow[t]{2}{*}{ Work to unemployment } & $<21$ & $1.36(1.05-1.77)^{*}$ & $1.50(1.10-2.03)^{*}$ \\
\hline & $\geq 21$ & $1.00(-)$ & $1.00(-)$ \\
\hline \multirow[t]{2}{*}{ Work to TO } & $<21$ & $1.15(1.01-1.30)^{*}$ & $1.15(0.97-1.36)$ \\
\hline & $\geq 21$ & $1.00(-)$ & $1.00(-)$ \\
\hline \multirow{2}{*}{$\begin{array}{l}\text { Work/sick/unemployment/TO } \\
\text { to disability }\end{array}$} & $<21$ & $3.65(2.26-5.88)^{*}$ & $5.28(2.92-9.54)^{*}$ \\
\hline & $\geq 21$ & $1.00(-)$ & $1.00(-)$ \\
\hline \multirow{2}{*}{$\begin{array}{l}\text { Work/sick/unemployment/ } \\
\text { TO to PO }\end{array}$} & $<21$ & $0.90(0.49-1.66)$ & $0.82(0.36-1.88)$ \\
\hline & $\geq 21$ & $1.00(-)$ & $1.00(-)$ \\
\hline \multirow[t]{2}{*}{ Sick to work } & $<21$ & $0.68(0.49-0.93)^{*}$ & $0.71(0.49-1.01)$ \\
\hline & $\geq 21$ & $1.00(-)$ & $1.00(-)$ \\
\hline \multirow[t]{2}{*}{ Sick to unemployment } & $<21$ & $1.20(0.88-1.64)$ & $1.03(0.61-1.74)$ \\
\hline & $\geq 21$ & $1.00(-)$ & $1.00(-)$ \\
\hline \multirow[t]{2}{*}{ Sick to TO } & $<21$ & $1.33(0.98-1.81)$ & $0.72(0.46-1.14)$ \\
\hline & $\geq 21$ & $1.00(-)$ & $1.00(-)$ \\
\hline \multirow[t]{2}{*}{ Unemployment to work } & $<21$ & $0.75(0.60-0.92)^{*}$ & $0.71(0.54-0.95)^{*}$ \\
\hline & $\geq 21$ & $1.00(-)$ & $1.00(-)$ \\
\hline \multirow[t]{2}{*}{ Unemployment to sick } & $<21$ & $1.12(0.82-1.53)$ & $0.97(0.59-1.61)$ \\
\hline & $\geq 21$ & $1.00(-)$ & $1.00(-)$ \\
\hline \multirow[t]{2}{*}{ Unemployment to TO } & $<21$ & $0.70(0.59-0.83)^{*}$ & $0.58(0.47-0.71)^{*}$ \\
\hline & $\geq 21$ & $1.00(-)$ & $1.00(-)$ \\
\hline \multirow[t]{2}{*}{ TO to work } & $<21$ & $1.00(0.87-1.15)$ & $1.09(0.88-1.34)$ \\
\hline & $\geq 21$ & $1.00(-)$ & $1.00(-)$ \\
\hline \multirow[t]{2}{*}{ TO to sick } & $<21$ & $2.23(1.45-3.41)^{*}$ & $0.98(0.56-1.72)$ \\
\hline & $\geq 21$ & $1.00(-)$ & $1.00(-)$ \\
\hline \multirow[t]{2}{*}{ TO to unemployment } & $<21$ & $1.31(1.07-1.60)^{*}$ & $1.17(0.88-1.55)$ \\
\hline & $\geq 21$ & $1.00(-)$ & $1.00(-)$ \\
\hline
\end{tabular}

* $5 \%$ significant.

$\mathrm{CL}$, confidence limits; ERP, early retirement scheme; MDI, Major Depression Inventory; PO, permanently out; TO, temporary out.

\section{Strengths and limitations}

Our study has several strengths. The multistate approach is unique as it includes permanent and multiple recurring labour market states over a period of 5 years among a large sample of Danish employees. ${ }^{26}$ This allowed us to examine timevarying effects, while adjusting for several important potential confounders. The study also has limitations. Depressive symptoms are only measured at baseline. For a more realistic approach, multiple individual measurements of depressive symptoms during follow-up should be taken into account. Moreover, depressive symptoms were self-reported, but showed a clear association with the prospectively collected information about labour market affiliation, that is, less time in work. Furthermore, we cannot rule out that other unknown causes or unmeasured constructs may impact labour market affiliation, for example, the presence of supportive family members or the inclusiveness of the particular workplace. Information on chronic diseases, comorbid with depressive symptoms, or recent life events may also have improved our estimates. Although our study is based on a relatively large sample of Danish employees and includes several covariates, the results should be repeated on larger sample sizes and in another jurisdictional context.

Even though the WLE estimates are prognostic in nature, they cannot be related to significant changes in the labour market which did not also happen during the follow-up period. Additionally, the prognostic nature is based on the theoretical assumption that by cumulating the behaviour of certain employees with the same profile and of different ages, one can create a profile-specific behavioural pattern that represents all ages.

Several covariates, for example, smoking and BMI, may act as confounders and/or mediators of depressive symptoms and may have influenced the results. Assuming that, for example, a high BMI leads to depressive symptoms, then a part of the WLE effect caused by depressive symptoms may be removed by using a weighted sample also based on BMI.

Our findings on the significant impact of depressive symptoms on WLE are relevant for both public and occupational health professionals and policymakers as the level of depressive symptoms in the general working population in Europe is high and increasing. ${ }^{2}$ The time lost in productive work and the increased time in unemployment and sickness absence for employees with depressive symptoms underline the need for integrating a life course perspective to work and health research and practice. ${ }^{38} \mathrm{~A}$ recent systematic review and meta-analysis identified three randomised controlled trials examining the effectiveness of psychological and educational interventions for the prevention of depression at the workplace with moderate effect, but low quality of evidence. ${ }^{39}$

\section{CONCLUSION}

The findings showed that the WLE was shorter for women and for men reporting depressive symptoms. The time in work was shorter, while the time in unemployment and sickness absence was longer. Moreover, employees with an ERP scheme spend less time in unemployment and sickness absence. The findings underline the need for effective workplace interventions for preventing and/or reducing depressive symptoms in the working population to maintaining employees' mental health during the entire working life.

Contributors JP wrote the original manuscript draft, designed the study and conducted the analysis. SVT, MFA, TNH and VS helped write the manuscript and contributed to the interpretation of the results. UB oversaw the study design and interpretation of the results, and helped write the final manuscript. The corresponding author had full access to all the data and had final responsibility to submit for publication.

Funding This study was funded by the Nordforsk project grant (ID: 76659) and by the National Research Centre for the Working Environment in Denmark. The funder of the study had no role in study design, data collection, data analysis, data interpretation or writing of the report.

Competing interests None declared.

\section{Patient consent for publication Not required.}

Ethics approval According to Danish law, research studies that use solely questionnaire and register data do not need approval from the National Committee on Health Research Ethics (Den Nationale Videnskabetiske Komité).

Provenance and peer review Not commissioned; externally peer reviewed. Data availability statement Data may be obtained from a third party and are not publicly available.

Open access This is an open access article distributed in accordance with the Creative Commons Attribution Non Commercial (CC BY-NC 4.0) license, which permits others to distribute, remix, adapt, build upon this work non-commercially, and license their derivative works on different terms, provided the original work is properly cited, appropriate credit is given, any changes made indicated, and the use is non-commercial. See: http://creativecommons.org/licenses/by-nc/4.0/.

\section{ORCID iDs}

Jacob Pedersen http://orcid.org/0000-0003-4429-3485

Ute Bültmann http://orcid.org/0000-0001-9589-9220 


\section{REFERENCES}

1 Whiteford HA, Ferrari AJ, Degenhardt L, et al. The global burden of mental, neurological and substance use disorders: an analysis from the global burden of disease study 2010. PLoS One 2015;10:eCollection 2015.

2 Parent-Thirion A, Biletta I, Cabrita J. Sixth European working conditions survey overview report Eurofound; 2016.

3 Tal og fakta om arbejdsmiljøet, 2019. Available: arbejdsmiljodata.nfa.dk

4 OECD. Mental health and work, 2014. Available: www.oecd.org/health/mentalhealth-and-work.htm

5 Lagerveld SE, Blonk RWB, Brenninkmeijer V, et al. Work-focused treatment of common mental disorders and return to work: a comparative outcome study. J Occup Health Psychol 2012;17:220-34.

6 Alavinia SM, Burdorf A. Unemployment and retirement and ill-health: a cross-sectional analysis across European countries. Int Arch Occup Environ Health 2008;82:39-45.

7 Bültmann U, Rugulies R, Lund T, et al. Depressive symptoms and the risk of long-term sickness absence: a prospective study among 4747 employees in Denmark. Soc Psychiatry Psychiatr Epidemiol 2006;41:875-80.

8 Bültmann U, Christensen KB, Burr H, et al. Severe depressive symptoms as predictor of disability pension: a 10-year follow-up study in Denmark. Eur J Public Health 2008;18:232-4.

9 Lerner D, Adler DA, Chang $\mathrm{H}$, et al. Unemployment, job retention, and productivity loss among employees with depression. PS 2004;55:1371-8.

10 Adler DA, McLaughlin TJ, Rogers WH, et al. Job performance deficits due to depression. Am J Psychiatry 2006;163:1569-76.

11 Erskine HE, Moffitt TE, Copeland WE, et al. A heavy burden on young minds: the global burden of mental and substance use disorders in children and youth. Psychol Med 2015;45:1551-63.

12 Patel V. Commentary: preventing suicide: need for a life course approach. Int J Epidemiol 2007;36:1242-3.

13 OECD. Rising youth unemployment during the crisis: how to prevent negative long-term consequences on a generation? OECD social, employment and migration working papers OECD Publishing; 2010.

14 OECD. Sick on the job? Myths and realities about mental health and work, mental health and work OECD Publishing; 2012.

15 Willekens FJ. Multistate analysis: tables of working life. Environ Plan A 1980;12:563-88.

16 Smith SJ. Tables of working life: the increment-decrement model: bulletin 2135 (February). Washington (DC) US Department of Labor, Bureau of Labor Statistics; 1982.

17 Nurminen M, Nurminen T. Multistate worklife expectancies. Scand J Work Environ Health 2005:31:169-78.

18 Dudel C, López Gómez MA, Benavides FG, et al. The length of working life in Spain: levels, recent trends, and the impact of the financial crisis. Eur J Popul 2018;34:769-91.

19 Loichinger E, Weber D. Trends in working life expectancy in Europe. J Aging Health 2016;28:1194-213.

20 Pedersen J, Bjorner JB. Worklife expectancy in a cohort of Danish employees aged 55-65 years - comparing a multi-state Cox proportional hazard approach with conventional multi-state life tables. BMC Public Health 2017;17:879.

21 de Wind A, van der Noordt M, Deeg DJH, et al. Working life expectancy in good and poor self-perceived health among Dutch workers aged 55-65 years with a chronic disease over the period 1992-2016. Occup Environ Med 2018;75:792-7.
22 Sirén M, Viikari-Juntura E, Arokoski J, et al. Work participation and working life expectancy after a disabling shoulder lesion. Occup Environ Med 2019;76:363-9.

23 Danmarks Statistik. Ligestilling i Danmark, 2019. Available: www.dst.dk/da/Statistik/ emner/levevilkaar/ligestilling/ligestillingswebsite\#3

24 Madsen PK, CARMA. How can it possibly fly? The paradox of a dynamic labour market in a Scandinavian welfare state Aalborg university: CARMA research papers; 2005.

25 Burr $\mathrm{H}$, Hasselhorn HM, Kersten $\mathrm{N}$, et al. Does age modify the association between psychosocial factors at work and deterioration of self-rated health? Scand J Work Environ Health 2017;43:465-74.

26 Török E, Hansen Åse Marie, Grynderup MB, et al. The association between workplace bullying and depressive symptoms: the role of the perpetrator. BMC Public Health 2016;16:993.

27 Bech P, Rasmussen NA, Olsen LR, et al. The sensitivity and specificity of the major depression inventory, using the present state examination as the index of diagnostic validity. J Affect Disord 2001;66:159-64.

28 Olsen LR, Jensen DV, Noerholm V, et al. The internal and external validity of the major depression inventory in measuring severity of depressive states. Psychol Med 2003;33:351-6.

29 Cuijpers P, Dekker J, Noteboom A, et al. Sensitivity and specificity of the major depression inventory in outpatients. BMC Psychiatry 2007;7:39.

30 Forsell Y. The major depression inventory versus schedules for clinical assessment in neuropsychiatry in a population sample. Soc Psychiatry Psychiatr Epidemiol 2005;40:209-13.

31 Bech P, Timmerby N, Martiny K, et al. Psychometric evaluation of the major depression inventory (MDI) as depression severity scale using the lead (longitudinal expert assessment of all data) as index of validity. BMC Psychiatry 2015;15:190.

32 Melkevik O, Clausen T, Pedersen J, et al. Comorbid symptoms of depression and musculoskeletal pain and risk of long term sickness absence. BMC Public Health 2018;18:981.

33 O'Dea B, Lee RSC, McGorry PD, et al. A prospective cohort study of depression course, functional disability, and NEET status in help-seeking young adults. Soc Psychiatry Psychiatr Epidemiol 2016;51:1395-404.

34 Veldman K, Reijneveld SA, Ortiz JA, et al. Mental health trajectories from childhood to young adulthood affect the educational and employment status of young adults: results from the trails study. J Epidemiol Community Health 2015:69:588-93.

35 Kaspersen SL, Pape K, Vie Gunnhild $\AA$, et al. Health and unemployment: 14 years of follow-up on job loss in the Norwegian HUNT study. Eur J Public Health 2016;26:312-7.

36 Evensen M, Lyngstad TH, Melkevik O, et al. Adolescent mental health and earnings inequalities in adulthood: evidence from the Young-HUNT study. J Epidemiol Community Health 2017;71:201-6.

37 Steel Z, Marnane C, Iranpour C, et al. The global prevalence of common mental disorders: a systematic review and meta-analysis 1980-2013. Int J Epidemiol 2014:43:476-93.

38 Amick BC, McLeod CB, Bültmann U. Labor markets and health: an integrated life course perspective. Scand J Work Environ Health 2016:42:346-53.

39 Bellón Juan Ángel, Conejo-Cerón S, Cortés-Abela C, et al. Effectiveness of psychological and educational interventions for the prevention of depression in the workplace: a systematic review and meta-analysis. Scand J Work Environ Health 2019;45:324-32. 